\title{
El intelecto agente según Teodorico El Teutónico*
}

The agent intellect according to Theodoricus Teutonicus

O intelecto agente segundo Teodorico 0 Teutônico

Fecha de entrega: 5 de febrero de 2015

Fecha de evaluación: 5 de octubre de 2015

Fecha de aprobación: 15 de enero de 2016

Juan Fernando Sellés**

\section{Resumen}

En este trabajo se estudia la concepción de Teodorico el Teutónico sobre el nivel cognoscitivo superior humano: el intelecto agente. De él este pensador medieval (ss. XIII-XIV) indica que es siempre activo, distinto en cada persona humana, superior al alma humana, imagen de Dios y abierto a él, pues la visión beatífica depende del intelecto agente.

Palabras clave: Teodorico el Teutónico, conocer humano superior, intelecto agente, visión beatífica.

* Este artículo hace parte de las investigaciones que el autor ha desarrollado sobre antropología medieval, especialmente en el tema de la teoria del conocimiento y su relación entre libertad y Dios. DOI: http:// dx.doi.org/10.15332/s0120-8462.2016.0114.03

* Doctor en Filosofía de la Universidad de Navarra, profesor de Antropología Filosófica, así como docente invitado de varias universidades extranjeras. Autor de varios libros y artículos científicos, entre ellos, Los hábitos intelectuales según Tomás de Aquino y ¿Acto de ser personal o existencia en el pensamiento de Kierkegaard?, conferencista de congresos internacionales, especialmente en las líneas de investigación de Antropología y Teoria del Conocimiento. Correo electrónico: jfeselles@unav.es 


\section{Abstract}

In this work we study the concept of agent intellect according to Theodoric the Teutonic. This medieval thinker (ss. XIII-XIV) indicates that it is always active, different in every human person, above the human soul, the image of God and open to him, and also that the beatific vision depends on the agent intellect.

Keywords: Theodoric the Teutonic, superior human knowledge, agent intellect, beatific vision.

\section{Resumo}

Neste trabalho, é estudado o conceito de Teodorico o Teutônico sobre o nível cognitivo superior humano: o intelecto agente. Dele este pensador medieval (ss. XIII-XIV) indica que está sempre ativo, diferente em cada pessoa humana, superior à alma humana, imagem de Deus e aberto para ele, pois a visão beatífica depende do intelecto agente.

Palavras-chave: Teodorico o Teutônico, conhecer humano superior, intelecto agente, visão beatífica. 


\section{Introducción}

Dietrich de Freiberg, Thierry de Fribourg o Teodorico el Teutónico, Maestro de Vriberg (1250-1310/20), fue un dominico que tuvo la suerte de vivir en París, Estrasburgo y Colonia en el momento álgido de la escolástica, plazas en que se debatía con profundidad el tema que nos ocupa. Como los otros grandes maestros de ese periodo, lejos de desentenderse de los temas más altos y de los métodos cognoscitivos superiores para alcanzarlos, tuvo la prerrogativa de encararlos de frente, y por lo que respecta al intellectus agens, lo abordó con mayor profundidad que sus colegas académicos. De manera que estamos ante una de las cimas — si no la superior- en lo que al desvelamiento de la índole del intelecto agente se refiere ${ }^{1}$.

En el Corpus Philosophorum Teutonicorum Medii Aevi están publicadas en 4 volúmenes las obras del Magistri de Vriberg. Anteriormente se publicó en la revista Beiträge (Krebs, 1906) el elenco de sus cerca de 40 obras, repartidas en los siguientes campos: 6 de lógica; 14 de filosofía de la naturaleza; 11 de teología; 2 pastorales; 8 de psicología, teoría del conocimiento y sobre la voluntad ${ }^{2}$. De entre estas últimas, dos escritos sobresalen en el estudio del intelecto agente, que por orden de superior a inferior son: el De visione beatifica y el Tractatus de intellectu et intelligibili. Junto a ellos, el escrito teológico Quaestio utrum in Deo sit aliqua vis cognoscitiva inferior intellect $u^{3}$ también aborda el tema. Con todo, hay alusiones al intelecto agente en

1 En este punto coincido con la declaración de Kurt Flash en la introducción al libro: DIETRICH DE FREIBERG, Ouvres choisies, I, Substances, quidités et accidens, Paris, Vrin, 2008, trad. et notes de C. Köning-Pralong et R. Imbach. Dice asi: "II n'a pas été complètement oublié. Cependant, il y a une nouvelle étoile à découvrir au ciel de la philosoplie européenne : Dietrich, venant de Freiberg", 7. Como anécdota histórico-filosófica, cabe recordar que es una pena que E. Krebs recomendase a su joven amigo Martin Heidegger escribir su tesis de habilitación sobre el Tractatus de origine rerum praedicamentalium de Dietrich, que Martin atribuia a Escoto, pues de haberle recomendado escribir sobre las obras en que el Magistri Theodorici trata del intelecto agente, $y$ haber seguido tal recomendación, es probable que al final de su vida Heidegger no hubiese tenido que lamentar que de haberse fijado antes en el intelecto agente, toda su filosofia hubiese sido completamente distinta.

2 Agrupamos en este campo las siguientes: De intellectu sive de visione beatifica; Quaestio de intellectu; De intellectu et inteligibili; De cogitione entium separatorum; De intelligentiis et motoribus caelorum, Quod substantia spiritualis non sit composita ex materia et forma; De habitibus; De voluntate.

3 Cfr. MAGISTRI THEODORICI, De visione betatifica y Tractatus de intellectu et intelligibili, en Corpus Philosophorum Teutonicorum Medii Aevi, Felix Meiner Verlag, Hamburg, vol., I, 2009, 9-124 y 131-210 respectivamente. La Quaestio utrum in Deo sit aliqua vis cognoscitiva inferior intellectu se encuentra en el vol. III, 2009, 283-315. 
otros de sus escritos. Por lo demás, es una lástima que se haya perdido su Comentario a las Sentencias, en el que también se debió ocupar de este asunto.

De su filosofía se ha dicho que sigue un planteamiento netamente neoplatónico. Pero esto no es verdad, al menos en el punto que nos ocupa, pues si bien leeremos que el intelecto agente 'emana' de Dios, Teodorico afirma que es creado, a la par que niega el monismo. Asimismo, si bien describe al intelecto agente como 'sustancia', no la entiende como 'separada', sino humana. Con esto se opone al pensamiento árabe y, de paso, niega que sea un 'accidente', con lo que se enfrenta a la opinión tomista que lo considera un accidente. Como veremos, en esto acierta más que el de Aquino. Por otra parte, también se le ha encuadrado dentro de los autores que conforman la llamada mística renana. Pero tampoco esto es correcto, porque sus escritos son netamente intelectuales, filosóficos. De igual forma, a su pensamiento se le han adherido las etiquetas de agustinismo reaccionario y de avicenismo cristiano. Sin embargo, no es ni lo uno ni lo otro; lo primero, porque lejos de oponer la doctrina agustiniana al corpus del Estagirita (como Escoto) los compatibiliza, como comprobaremos al estudiar este tema, el más alto de los humanos; lo segundo, porque el corazón de su filosofía no es la metafísica (como en el filósofo árabe), sino la teoría del conocimiento, y en esta su núcleo es el intelecto agente humano (no el 'angélico', como en el pensador persa). También se ha indicado que su teoría del conocimiento es una 'construcción intelectual' (Mojsisch, 1997). Pero tampoco lo es, sino que responde a finos descubrimientos de temas de fondo.

¿A qué autores precedentes, además de Aristóteles, conoce este dominico en esta cuestión? A una lista nada despreciable: Alejandro de Afrodisia, Alfarabí, Avicebron, Averroes, Avicena, Alberto Magno, San Buenaventura, Tomás de Aquino, Meister Eckhart, Siger de Brabante (Flash, 2008), Pedro Hispano, Gonzalo de España, Egidio Romano, Enrique de Gante, Bernardo de Tillia, Godofredo de Fontibus, Mateo de Aquasparta, Pedro Juan Olivi, Ricardo de Mediavilla, Roberto Grosseteste, Roger Bacon, etc. ¿Con cuál de ellos guarda más similitud su filosofía? Algunos piensan que con Meister Eckhart, pero, en rigor, este no estudió el tema del intelecto agente. Seguramente, lo que buscaba Teodorico en este tema era continuar a Aristóteles intentándolo compatibilizar con el pensamiento de San Agustín. En efecto, Aristóteles y Agustín de Hipona son los dos modelos que Dietrich sigue y pone de acuerdo. A lo que precede, se puede objetar que tras las críticas de Gilson a San Agustín de manos de Tomás de Aquino, seguramente se dirá que el empeño de conciliar aristotelismo 
y agustinismo está llamado al fracaso. No obstante, aunque parezca haber oposición doctrinal entre el corpus tomista y el agustiniano por lo que a la teoría del conocimiento se refiere, recuérdese que el de Aquino siguió en todo lo que pudo a San Agustín y que, a su vez, Aristóteles fue para el Doctor Angélico el Filósofo por excelencia. De modo que, si ambos descubrieron verdades de fondo, estas no podían estar en contradicción. Y esa actitud conciliadora del Aquinate se repite, y se acrecienta, en el autor que nos ocupa.

Es llamativo que Teodorico no siguiese a San Alberto Magno y, sobre todo, a Santo Tomás de Aquino en puntos clave del pensamiento de aquellos, siendo asimismo dominico, conocedor de su filosofía y e inmediatamente posterior a ellos. En efecto, Dietrich se opuso a algunas piezas clave del pensamiento tomista ${ }^{4}$ (Imbach, 1997; Winkler, 1999). De haberlas tenido en cuenta y haberlas vinculado a sus propios descubrimientos hubiese continuado el pensamiento tomista superándolo desde dentro. ¿Por qué lo hizo? Para Mauer e Imbarch esta oposición se concreta en varios puntos de la filosofía y teología (Imbach, 1979; Maurer, 1956); para Alain de Librea, sobre todo, a un aspecto (al que aquí se aludirá) que según él afecta a la par a la ontología y a la teoría del conocimiento: el ens conceptionale (1984, p. 166). La respuesta a esta cuestión, a la que no podemos responder globalmente, queda abierta a la futura investigación historiográfica. Pero sí podemos decir, con seguridad, que gracias a no seguir el punto de vista de Tomás de Aquino en el tema del intelecto agente, lo rectificó y lo superó ampliamente. Efectivamente, más que lamentar la falta de continuidad filosófica de Dietrich con el de Aquino, lo lamentable es que la historia posterior haya tenido en cuenta sobre esta materia la opinión tomista y haya olvidado la teutónica.

\section{El intelecto agente según el De visione beatifica}

La Tabula o Índice de este trabajo se divide en cuatro apartados, cada uno de los cuales contiene múltiples epígrafes. En ella se encuentran muchos ítems en los que se hace referencia explícita al intelecto agente ${ }^{5}$. Con todo, en los demás, en los que

4 Se opuso a la distinción real tomista essentia-actus essendi, que considera meramente racional; pero esto es erróneo.

5 1. Intellectus agentis in ordine ad Deus.

1.1. Intellectus agens ut substantia.

1.1.1. Intellectus agens ut imago Dei est substantia.

1.1.2. Intellectus agens semper actu intelligit. 
esta expresión no aparece en el título, se trata también de él. Lo primero que llama la atención es que los temas que se proponen a indagación en este elenco son muy interesantes. En efecto, en el Proemio de esta obra se indica que se va a tratar de qué es lo supremo en el hombre tocante a la beatitud, es decir, "lo superior que Dios plantó en nuestra naturaleza por la que accedemos a él” (Magistri, 2009, p. 14). Seguidamente se indica que la distinción agustiniana entre intelecto oculto ('abstruso') o profundo ('abdito') e intelecto exterior ('exteriore', 'cogitativum') es equivalente a la aristotélica de 'intelecto agente' e 'intelecto posible'6, comparación que carece - hasta donde sabemos- de precedentes. Ya desde este Proemio Teodorico avanza que, referido el intelecto agente a su tema y el posible al suyo, el primero 'incomparabiliter praeeminet et gradu suae entitatis excedit' al segundo. Añade, asimismo, que es el primero, no el segundo, el que toca a la beatitud. Para demostrarlo - advierte - dividirá el estudio en 4 partes $^{7}$, tres de las cuales $\left(1 .^{\mathrm{a}}, 3 .^{\mathrm{a}} \mathrm{y} 4 .^{\mathrm{a}}\right)$ carecen de antecedentes doctrinales, y en la restante (la 2. a), ya discutida por pensadores anteriores, Dietrich ofrece un planteamiento del todo nuevo y agudo. Seguidamente, se dedicará un epígrafe a exponer, en síntesis, el quid de cada una de estas partes.

1.1.3. Intellectus agens se ipsum intelligit per suam essentiam.

1.1.5. Intellectus agens sicut se ipsum, sic omnia alia intelligit per suam essentiam.

1.1.9. Sententia omnium peripateticorum et Augustini, quod intellectus agens est substantia.

1.2. Intellectus agens ut imago Dei.

1.2.1.1. Ratio sumpta ex modo processionis intellectus agentis a Deo et reductionis in Deum.

1.2.1.1.7. Intellectus agens perfecte et proprie imago Dei est ratione suae emanationis a suo principio et reductionis in suum principium.

2. Ordo intellectus agentis ad alia.

3. Impossibile est visionem beatificam fieri per intellectum possibilem.

4. De modo visionis beata.

6 "Quod quamvis verbis aliis, non tamen in sententia discrepans invenimus apud philosopos, qui distinguunt in intellectuali nostro intellectum agentem ab intellectu possibili, ut idem sit intellectus agens apud philosophos, quod abditum mentis apud Augustinum, et intellectus possibilis apud philosophos idem, quod exterius cogitativum secundum Augustinum. Quod ex eo patet quod quidquid umquam Philosophus tractavit de intellectu agente et possibili, totum verificatur de abdito mentis et exteriore cogitativa secundum Augustinum" (Magistri, 2009, p. 14). Para esclarecer las diversas denominaciones que Teodorico da a los intelectos: B. MOJSISCH, Die Theorie des intellects bei Dietrich von Freiberg, Hamburg, Felix Meiner Verlag, 1977.

7 Estas cuatro partes son las siguientes:

I.a) El intelecto agente en orden a Dios.

II.) El orden del intelecto agente al posible.

III.a) La imposibilidad de que intelecto posible alcance la visión beatífica.

IV.a) El modo como la visión beatífica perfecciona al intelecto agente. 


\section{I. Parte: el intelecto agente en orden a Dios}

En esta parte Teodorico se propone mostrar 4 asuntos sobre el intelecto agente (al que llama 'conocer escondido'): 1) Es la sustancia humana. 2) En él radica la imagen y semejanza de Dios. 3) Es esencialmente capaz de Dios por su intelección. 4) Se convierte a Dios por su esencia, que no difiere de su operación. Estas 4 proposiciones son las afirmaciones más relevantes que hasta su momento histórico se redactaron sobre este tema. A continuación se resume su contenido doctrinal.

1. El intelecto agente como imagen de Dios es sustancia. La imagen de Dios en nosotros - afirma Teodorico- está en la mente, no en el cuerpo; en concreto, en el intelecto agente. La semejanza, en cambio, pertenece al conocimiento exterior o entendimiento posible. No le puede convenir a este la imagen — añade—, por una razón obvia: 'cum sit ens pure in potentia's. Lo que precede es tan correcto como olvidado por los filósofos anteriores al Maestro de Vriberg y, asimismo, por los posteriores a él hasta la segunda mitad del s. XX ${ }^{9}$. A continuación rebate la ancestral tesis de radicar la imagen divina en el hombre en las potencias superiores: 'inteligencia' y 'voluntad', a la que añade la 'memoria' como 'hábito de las especies', porque esa imagen es defectiva, ya que solo puede quedar referida a los actos y hábitos ‘adquiridos' y, por lo mismo, no es 'natural' u originaria; de lo que se seguiría que el hombre, antes de adquirirlos, no es imagen de Dios sino en potencia ${ }^{10}$ (Magistri, 2009, p. 16). Esta afirmación es, llanamente, tan sencilla como genial y verdadera.

A lo que precede Teodorico agrega que lo que constituye en nosotros tal imagen debe ser 'sustancia', y lo expone con estas palabras:

8 Esa razón es tan clara y verdadera como llamativamente desconocida por los pensadores precedentes. En efecto, ¿por qué tanta insistencia en buscar la imagen divina en la inteligencia y en la voluntad, si estas son potencias pasivas, tabula rasa? ¿Por qué ese empeño por buscar en las potencias lo que no puede ser sino acto?

9 Como veremos, en la segunda mitad del s. XX, ha habido dos pensadores que han defendido que el intelecto agente es acto, no como 'operación inmanente' o 'hábito', sino como acto de ser: Francisco Canals y Leonardo Polo. Ambos, al formular sus propuestas, desconocieron por completo el parecer de Teodorico. El primero murió sin saber de él. Por lo que al segundo respecta, cuando supo en 2011 la existencia y opinión del teutónico al respecto se alegró sobremanera y animó a proseguirla.

$10 Y$ añade: "requiritur autem ad perfectam rationem imaginis, ut sit aliquid secundum naturam mentis et semper in actu". 
La imagen se dice más propiamente según cierta conformidad sustancial supuesto el origen de uno a otro como cierta consustancialidad de la imagen a lo imaginado (...). La razón de imagen consiste solo en la conformidad de la sustancia. Por tanto, eso que es formalmente imagen de Dios en nosotros es sustancia (Magistri, 2009, p. 17).

Explica que la vinculación de las personas divinas es sustancial, no accidental, y que nuestra vinculación con Dios también lo es ${ }^{11}$.

Como tal unidad de esencia y trinidad según la diferencia de origen está en la mente en cuanto a esta porción a la que Agustín llama mente escondida (o profunda) - y que según la verdad es el intelecto agente-, es manifiesto que él mismo es sustancia (Magistri, 2009, p. 18).

Lo cual confirma con la autoridad del mismo San Agustín, para quien la 'mente', la 'noticia' y el 'amor' son consustanciales o de una esencia, 'porque exceden a su sujeto', no accidentales (Ibid., pp. 18-19). Que esto no se puede predicar del intelecto posible es claro, porque los objetos por él conocidos — completa Dietrich- no exceden a su sujeto, ya que, o lo conocido es él mismo, o son objetos inferiores a él, afirmaciones asimismo correctas.

En la precedente exposición, el término 'sustancia' es matizable, porque en sentido estricto una sustancia es un compuesto hilemórfico, es decir, dos concausas inseparables (la material y la formal). En cambio, el intelecto agente no es causa formal o concausa ninguna y, por eso (como Aristóteles advirtió), es separado de la materia y del cuerpo humano. No obstante, si 'sustancia' se toma en sentido lato, en el de 'subsistencia' (como por lo demás lo tomó Tomás de Aquino al atribuirlo a la persona, y como asimismo lo toma Teodorico), no hay problema en predicarlo del intelecto agente o de la persona. Téngase en cuenta también que el Maestro de Vriberg lo llama 'sustancia' debido a la traducción latina que usa del texto griego, pues allí donde Aristóteles escribe que el intelecto agente 'es acto por su propia entidad', las

11 Este planteamiento tiene la ventaja de advertir que la vinculación del hombre con Dios es 'natural' y 'radical', no adquirida, periférica o electiva. Nótese que esa doctrina soluciona avant la lettre la discusión renacentista (y posterior) acerca de si la 'la relación' es un mero accidente o, por el contrario, es subsistente. 
traducciones que este Maestro escolástico emplea dicen: 'substantia actu ens', 'est in sua substantia actio' (Ibid., p. 24).

Por el contrario, el intelecto posible - afirma - no es 'sustancia' en el sentido aludido. Sí, en cambio, la 'mente oculta', por cinco razones:

Primero, porque siempre permanece en la luz actual de la inteligencia y siempre entiende; segundo, porque por tal intelección se entiende a sí mismo por su esencia; tercero (...) porque es cierta semejanza o ejemplar de todo ente en él (...) ; cuarto, porque entiende, como a sí mismo, a las demás cosas por su esencia y del mismo modo que se entiende a sí mismo, y con la misma simple intelección; quinto (...) porque excede su sujeto (Magistri, 2009, p. 22).

A continuación pasa a fundamentar cada una de estas razones:

1. a) El intelecto agente siempre entiende en acto, porque 'es intelecto por esencia', por tanto, es necesario que siempre sea fijo en el mismo modo de su sustancia. "Así pues, si entiende, siempre entiende" (Ibid., p. 22). Si su esencia es intelectual, separada, inmixta, entiende siempre. De lo contrario, la expresión aristotélica de intelecto agente' sería pura denominación. Si no entendiera siempre, sería porque en él había disposiciones extrañas al entender, pero es intelecto por esencia $y$, precisamente por eso, es superior al posible (pp.23-24). Compara la constante actividad de este intelecto a lo que dice San Agustín respecto de la mente escondida, que 'siempre se recuerda, se conoce, se ama'.

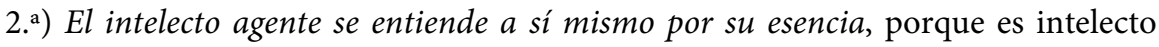
por esencia, como el hombre es hombre por naturaleza. Si es intelecto por esencia, siempre opera, y su operación es su esencia ('non est distinguere inter substantiam et operationem'). Por tanto, se conoce a sí por su operación o esencia, lo cual indica que la esencia del intelecto agente es 'simplex' (Ibid., pp. 26-27). Teodorico sabe que ningún otro conocimiento humano se conoce a sí mismo, sino que conoce lo otro, y así lo expone respecto del sentido y de la razón. ¿Qué otra distinción cabe entre el intelecto agente y los demás conocimientos? En que los otros reciben, mientras que el agente $\mathrm{no}^{12}$ (pp. 27-28). Por lo demás, que el intelecto agente se conozca, no obsta

12 Más adelante indica que ese conocimiento propio solo analógicamente se puede llamar 'reflexión': "in se ipsum semper reflexus est, si tamen potest dici reflexio, ubi vere est directa suae essentiae 
— para el Maestro Teutónico- que sea abierto a un conocer superior a él ${ }^{13}$. Lo que precede indica que los conocimientos inferiores al intelecto agente son iluminantes, es decir, como foco, mientras que el del intelecto agente es translúcido. Por lo demás, que lo translúcido es compatible con ser 'iluminado' por el conocer superior divino es claro; es más, solo así se conoce lo translucido.

3. $\left.{ }^{a}\right)$ El intelecto agente es cierta semejanza o ejemplar de todo ente en él, porque es de naturaleza universal y no está determinado a conocer esto o lo otro; por eso se dice de él que es 'intellectualiter quodammodo omne ens', lo cual no ocurre en él potencialmente -como en el intelecto posible-, sino según el acto (Ibid., p. 29), lo que concuerda - escribe Teodorico- con lo que indica San Agustín acerca de nuestra alma inmortal, que contiene en lo secreto de su ser todas las razones verdaderas.

4. a) El intelecto agente entiende, como a sí mismo, las demás cosas por su esencia, porque como por su esencia es el ejemplar de todo ente, entendiéndose a sí mismo de modo simple, entiende así todo ente (Ibid., pp. 30-31). Todas las cosas son potencia respecto de este acto. No es este acto para las potencias, sino a la inversa. Tal acto conoce todo lo inferior y es razón de ser de lo inferior; no al revés.

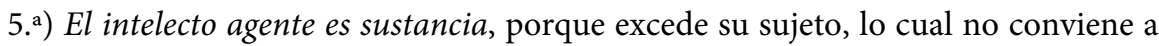
ningún accidente. Entendiéndose a sí mismo entiende las demás cosas por esencia y, por la misma simple intelección, se excede a sí mismo, lo cual no es propio de los accidentes por dos motivos: a) porque ningún accidente se refiere a sí mismo sino a lo otro; b) porque el accidente no está en sí, sino en el sujeto, mientras que el intelecto, estando en sí, conoce todo lo demás (Ibid., pp. 31-32). Tal intelecto no sale de sí para conocer el resto de la realidad, sino que insistiendo en sí descubre el ser de lo demás, porque lo inferior es para él y él para Dios, es decir, es coexistente.

Lo que precede lo corrobora con la autoridad de San Agustín, quien enseña, entre otras cosas, que en el alma hay ciertas 'verdades inmutables', de lo que el obispo de Hipona deduce (como es sabido) la inmortalidad e incorruptibilidad del alma (Ibid., pp. 33-34). En efecto, si el intelecto agente es siempre activo cognoscitivamente, la verdad temática a la que está abierto no puede ser sino siempre activa. Por el contrario,

intellectio" (Magistri, p. 31)

13 "Nihil intelligit extra se, videlicet primo et per se, sed solum in se ipsum conversus est et in suum principium, si habeat altius se principium" (Magistri, p. 28). 
el intelecto posible no siempre entiende en acto ciertas verdades inmutables, porque primero es potencia pasiva, y porque luego olvida. Por eso, si el intelecto escondido o agente "fuese cierta potencia al modo de accidente inherente en el sujeto del alma (...), el alma no sería inmortal” (p. 34). Esta tesis, que el intelecto agente sea sustancia, se aviene bien - añade - con lo que afirman los peripatéticos, aunque ellos lo digan de las sustancias separadas, mientras Aristóteles lo predica del alma. Es compatible también con lo que enseña el de Hipona, a saber, que la mente escondida, en la que pone la memoria, la inteligencia y la voluntad, es sustancia, no que las tres sean en la sustancia del alma, sino que las tres son una sustancia, porque las tres se refieren entre sí (pp. 35-36). Lo que precede indica que, si el intelecto agente forma parte de la intimidad humana, esta no es simple, sino conformada por diversas dimensiones, una de las cuales es dicho conocer personal.

\section{A continuación indaga sobre el intelecto agente como imagen de Dios, lo cual} se puede fundamentar - declara- por la razón y por argumentos de autoridad: lo primero, porque procede de Dios y a él se vuelve como a su principio; lo segundo, porque se dice (en el texto aristotélico) que es sustancia (según el sentido indicado de sustancia).

a) En cuanto a lo primero, saber por la razón que el intelecto agente es imagen de Dios, Teodorico enseña que las cosas pueden volverse a Dios como a su principio de cuatro modos: a) según su forma o especie; b) según cada uno de los individuos, cuyo ejemplar está en la mente divina; c) por la ciencia, vía propia de las criaturas racionales; d) por el intelecto en acto por esencia, en el que reluce de modo perfecto la imagen divina (Ibid., pp. 37-41).

Para la perfecta imagen divina se requiere que esta sea representativa del ser divino según su naturaleza o esencia. Ahora bien, el intelecto agente o mente escondida es perfecta y propia imagen de Dios por razón de que emana de su principio divino y de su vuelta a él (Magistri, 2009, pp. 42-43). En efecto:

Tal intelecto emana de su principio, Dios, de modo superior y más noble que las demás cosas producidas por Dios, pues en la producción de las demás cosas Dios dijo y fueron hechas (...) pero en tal intelecto (...) no fue así como en las demás cosas (...) sino (...) según formal flujo de su esencia (...) que es Dios, procediendo intelectualmente de ella y conociendo su esencia (...). Y emana intelectualmente de él de modo que su sustancia no es sino cierto concepto 
por el que concibe y entiende su principio, sin el cual no puede entender ni su propia esencia (Magistri, 2009, p. 43).

En suma, para Teodorico el intelecto agente es coexistente con el ser divino, pero dado que es intelecto, ese coexistir es intelectual, lo cual indica que tiene a Dios como a tema propio. Por lo demás, esto no significa que el intelecto agente conozca a Dios mirando fuera de sí: "al entender su principio, no conoce fuera de sí, sino que entiende su esencia más dentro de sí que en él” (Ibid., p. 43), lo cual equivale a decir que el intelecto agente, "al conocer su esencia, necesariamente conoce su principio" (p. 43). Como se ve, esto coincide con el agustiniano 'noli foras ire', e indica que el intelecto agente se conoce en la medida en que Dios lo ilumina, a la par que, por conocer esa iluminación, conoce que esa iluminación es divina, y en esa medida conoce a Dios.

Como el intelecto agente conoce su propia esencia, y en ella a su principio, este conocimiento es previo a cualquier otro conocimiento referido a las demás cosas (Ibid., p. 44). Lo que precede puede dar la impresión de ontologismo, pero este error se evade si se sostiene que el intelecto agente está abierto a Dios, pero que no abarca o comprende el término de esa referencia. De otro modo: conocemos a Dios en la medida en que nos ilumina, no en tanto que él se ilumina, pues la luz con que nos conoce es inferior a la luz mediante la que se conoce. Además, si el intelecto agente no se conoce enteramente a sí mismo (ni, por supuesto, a Dios y a las demás cosas), lo cual equivale a decir que, si no se conoce por completo, es porque el conocer que emplea para conocerse es inferior al conocer que él mismo es. Pero si es inferior no puede ser sino distinto. Ese conocer mediante el cual el alma se conoce nativamente a sí misma Tomás de Aquino lo denominaba 'hábito originario', y es claro que un hábito no es el intelecto agente, que es acto (pero no como operación o como hábito), lo cual apunta a decir que el conocimiento de sí es habitual, un hábito que es innato al intelecto agente: una habilitas suya, pero distinto de él. Por medido de este hábito sabemos que somos conocer en acto o intelecto agente, pero no que tal conocer está referido a Dios.

b) En cuanto a lo segundo, es decir, saber por autoridad que el intelecto agente sea imagen de Dios, Teodorico indica que Agustín de Hipona lo designaba como 'razón eterna y verdad inmutable', y hablaba de 'reglas eternas presentes en la mente' (Ibid., p. 44), lo cual indica que es perfecta imagen de Dios. Añade, además, que es imagen de Dios no solo en cuanto a la unidad, sino también en cuanto a la trinidad, pues tal 
intelecto "tiene en su sustancia unidad de esencia y trinidad de tres solo por respecto del origen de las diferencias, que son — según Agustín — la memoria, la inteligencia y la voluntad" (p. 44) ${ }^{14}$. De esto concluye que "la perfecta semejanza a Dios, que es la imagen de Dios, es la 'mente escondida', que es el intelecto por esencia” (p. 45). La voluntad a este nivel se puede entender como amor, pues el amor es siempre activo, mientras que la voluntad es potencia pasiva. Asimismo, por mente se puede entender ese aludido conocer (o hábito originario) solidario con el intelecto agente, por medio del cual nos sabemos tal conocer activo. $Y$ tales perfecciones se dan vinculadas, no por separado, es decir, no cabe una sin otra.

En contraposición a lo que precede, ahora Teodorico argumenta que el intelecto posible no es imagen de Dios, por cuatro razones, a saber: 1) porque no es sustancia; 2) no siempre está en acto de entender; 3 ) no se hace en acto sino por alguna especie; 4) "la memoria, inteligencia y voluntad, en cuanto que pertenecen al intelecto posible no son ad invicem coaeva nec semper simul" (Magistri, 2009, p. 46), porque la memoria precede a la inteligencia, y estas a la voluntad. Además, esas tres, en cuanto que pertenecen al intelecto posible no son iguales según sus propios actos, porque no es lo mismo pensar, recordar y querer (Ibid., p. 47). Con todo, estas tres, "en cuanto que se consideran respecto del intelecto posible hecho en acto, tienen cierta semejanza cercana a la verdadera imagen" (p. 47). Esto lo confirma por la autoridad de San Agustín, del que dice que nunca puso la verdadera imagen en el intelecto posible, al que pertenecen las ciencias humanas. Por eso Teodorico indica que las dos facetas del intelecto posible, denominadas por San Agustín 'ratio inferior' y 'ratio superior' no son perfecta imagen de Dios, porque ambas son, ante todo, 'ratio', es decir, conocimiento adquirido, mientras que la imagen y semejanza divina en nosotros es 'natural' (p. 48), nativa, y está 'in abdito mentis, quod est intellectus per essentiam semper in actu' (p. 50 ); por eso, tal imagen también se da en los niños sin uso de razón (sin activación

14 A eso añade que "haec tria, scilicet memoria, intelligentia, voluntas, sunt unum per essentiam, una essentia, una mens, una vita, una substantia, et quidquid essentialiter seu absolute de ipsis praedicatur, de singulis eorum in singulari praedicatur et de omnibus simul, non in plurali, sed in singulari praedicatur. Solum autem in hoc differunt, quod ad invicem referuntur... Sunt haec tria etiam sibi invicem coaeva et coequalia, quorum nihil prius aut posterius, nihil maius aut minus, simper eodem modo permanentia in tota mentis et ipsius animae perpetuitate... Sic ergo tria preadicta, scilicet memoria, intelligentia, vooluntas, sunt sibi invicem coaeva et immortali perpetuitate fixa in esse" (Magistri, 2009, p. 45). Como se ve, atribuye a tal mens, iltellectus y voluntas las notas que el Símbolo Quicumque atribuye a la Trinidad. Sin embargo, la criatura se caracteriza a todo nivel por la distinción jerárquica. De modo que esas tres dimensiones que conforman la intimidad o el acto personal deben ser jerárquicamente distintas. 
en el intelecto posible); imagen que es previa y superior a la que se alcanza cuando se adquieren hábitos cognoscitivos ( $\mathrm{y}$ asimismo virtudes) en el intelecto posible. Estas afirmaciones, tan agudas y verdaderas, carecen de antecedentes en la historia de la filosofía y, lamentablemente, de consecuentes.

Por lo demás, la mencionada imagen divina en el hombre se manifiesta 'ad exterius cogitativum' de tres modos: 1) por razón de objeto; 2) como causa eficiente; 3) como referencia formal, y esto último, o bien como acto o bien como potencia. Según la razón de objeto, porque produce el pensamiento de la razón y el querer de la voluntad. Según la razón de causa eficiente, porque toda la razón procede del intelecto agente. Según la razón de forma, porque el intelecto agente forma en el conocimiento exterior la semejanza divina (Ibid., pp. 51-53). Tras esto indica que "tal intelecto (el agente) es por su esencia algo subsistente a modo de supuesto"15 (p. 53), y -retomando la doctrina agustiniana- de él predica que se conoce a sí y a sí se ama, pero no conforma tres hipóstasis o personas, como en Dios (pp. 57-61); con todo, es perfecta imagen divina: "la imagen de Dios que Dios mismo plantó en nuestra naturaleza es expresa, sobre todo y de modo más perfecto que en otras cosas, en la 'abdito mentis nostrae', que es el intelecto agente por esencia” (p. 61).

3. ${ }^{\circ}$ ) El intelecto agente es capaz de Dios. Según lo que se acaba de indicar, el intelecto agente es más capaz de Dios que las demás potencias humanas. En efecto, el intelecto agente, por proceder del primer principio y ser imagen de Dios, siempre es capaz de Dios por su esencia; no, en cambio, el posible, que no obra por su esencia, sino por algo extrínseco (Ibid., p. 61).

4. $\left.{ }^{\circ}\right)$ El intelecto agente se convierte a Dios por su esencia, que no difiere de su operación. El intelecto agente, que por esencia procede de Dios, simultáneamente por su operación, que equivale a su esencia, se convierte a él ${ }^{16}$ (Ibid., pp. 61-62). Lo propio de las potencias y de los hábitos adquiridos es que las operaciones inmanentes que

15 Entiende tal sustancia como 'hoc aliquid', no como 'quale quid' (Magistri, 2009, p. 56).

16 En esto, Diectrich sigue el parecer de Boecio y de Proclo, y añade: "secundum hoc igitur substanta, quae est intellectus per essentiam semper in actu, qualis est intellectus, de quo agitur, quia per essentiam intellectualiter procedir a Deo, etiam sua intellectuali operatione, quae est essentia eius, semper convertitur in Deum ita, ut eius emanatio, qua intellectualiter emanat, per essentiam a suo principio, sit ipsius in ipsum principium intellectualis conversio. Non enim primo ab ipso procedit et postea alio respectu seu operatione in ipsum convertitur, sed eadem simplici intellectione, quae est essentia eius" (Magistri, 2009, pp. 62-63). 
proceden de esos principios son inferiores a ellos. En cambio, en el intelecto agente no cabe distinguir entre él y su operación, lo cual denuncia que predicar del intelecto agente la operación abstractiva (como es usual) es una lamentable reducción. Pero indica algo más, a saber que el intelecto agente se puede poner a nivel de acto de ser humano, pues todo conocer humano inferior a ese nivel admite distinción entre el principio cognoscitivo y la operación noética que nace de él.

Sentados estos cuatro puntos, Dietrich concluye que "él mismo (el intelecto agente) es lo supremo que procede de Dios como de principio inmediato según la forma, por el que nos unimos inmediatamente a Dios en la visión beatífica” (Magistri, 2009, p. 63). De ahí la conveniencia de ponerlo a nivel de acto de ser humano, o si se prefiere, a nivel de persona creada, pues es pertinente que entre esta y Dios no existan intermediarios, sino que su relación sea directa.

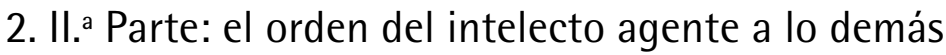

En esta parte el Maestro de Vriberg expone la relación del intelecto agente a dos realidades: a) al intelecto posible; b) a los demás entes no inteligentes.

a) Comienza este nuevo epígrafe exponiendo la triple referencia que el intelecto agente tiene respecto del posible: 1) como principio activo; 2) como el agente respecto de lo hecho; 3 ) en cuanto perfectivo del posible de doble modo: en la medida en que le otorga la forma, y en cuanto que lo reconduce a Dios en la beatitud, porque el intelecto agente es medio entre el acto puro, que es Dios, y la pura potencia, que es el posible $^{17}$ (Magistri, 2009, p. 64). Por otro lado, afirma que en la otra vida, el intelecto agente también se unirá a Dios más que el posible, aunque de modo diferente a como lo hace en esta (Ibid., pp. 64-65).

b) La relación del intelecto agente a las demás realidades corpóreas es de mediación entre ellas y Dios. En los ángeles o sustancias espirituales también se da el intelecto siempre en acto por su esencia (Ibid., p. 66). Suele repetirse que el hombre es para su

17 El intelecto agente reconduce al posible a Dios porque "sicut mediante intellectu agente intellectus possibilis procedit in actum et perfectionem suae propriae operationis, in quo et eius essentia constituitur in esse quantum ad actum suum formalem sibi essentialem, qui est species intelligibilis seu actualis intellectio eius, sic eodem processu est conversio eius in primum principium mediante intellectu agente, quia primo gradu et ordine regulae aeternae et incomunicabilis veritas praesentes sunt abdito mentis secundum Augustinum, quod est intellectus agens, quo mediante fulgent in intellecu possibili, quo et ipse conversus est in primum omnium principium, quod est Deus" (Magistri, 2009, p. 64). 
operación más propia, que es por el intelecto. Pero en el intelecto hay que distinguir entre la operación que es su esencia, la del intelecto agente, y la que es por participación, la del intelecto posible (p. 67). Por tanto:

\begin{abstract}
La operación intelectual que es por esencia, más aún, la que es la misma esencia del que obra, es más íntima, perfecta y noble y, por consiguiente, más cercana y penetrativa de la realidad entendida que esa operación intelectual que es por la forma en otro, que está fuera de la esencia del que obra (Magistri, 2009, p. 67).
\end{abstract}

En suma, el hombre es por la operación del intelecto agente - o mente profunda-, porque tal 'operación' es por la que el hombre es hombre, y es por ella por la que el hombre se une a Dios en la beatitud.

\title{
3. Ill. Parte: imposibilidad de alcanzar la visión beatífica por el intelecto posible
}

Esta parte se divide en dos apartados: a) negación de la tesis equivocada; b) fundamentación de la imposibilidad de alcanzar la beatitud por el intelecto posible. A estas partes Teodorico añade una curiosa digresión metafísica, que a primera vista parece no venir al caso, pero de la que se sirve después para negar que sea propia del intelecto posible la visión beatífica.

a) La visión beatífica no se realiza por el intelecto posible, porque tal operación debe ser la más perfecta, y esta es la propia de lo más noble en nosotros: 'el intelecto por esencia siempre en acto' (Magistri, 2009, p. 68). Pero si se reduce el papel de este a la abstracción de los fantasmas, en aquella vida carecería de sentido, porque no hay fantasmas. Por otra parte, si se conociese a Dios por el posible, se le conocería por especies, no por esencia. Además, si se admite que el intelecto agente es la causa de que el posible vea a Dios, hay que afirmar que de modo más alto y noble lo verá el agente, porque la causa siempre es superior al efecto (Ibid., p. 69). Si, además, se afirma que el intelecto agente no conoce (afirmación que califica de 'rudis positio', y que será lamentablemente aceptada hasta la saciedad en la Escolástica Renacentista y posteriormente):

Se seguiría que el intelecto agente no es ente intelectual en su naturaleza. (...).

También, que no haría nada intelectual de su parte y, por tanto, nada intelectual 
procedería de él... Añádase que él mismo sería de naturaleza inferior en grado que lo causado por él (Magistri, 2009, p. 69).

Lo cual es inadmisible, porque sencillamente es contradictorio. Como se puede advertir, estas afirmaciones son sensatas y acertadas, y rectifican avant la lettre muchos planteamientos renacentistas y subsecuentes al respecto que son poco perspicaces $y$ en gran medida reductivos.

b) Fundamentación de que el intelecto posible es incapaz de ver directamente a Dios. En la visión beatífica el intelecto posible puede estar de cuatro modos: 1) en potencia o carencia de acto primero y de acto segundo; 2) en acto respecto del acto primero $\mathrm{y}$ en potencia respecto del segundo (entender en acto); 3 ) en acto en cuanto al acto segundo, pero en potencia respecto del acto primero; 4$)$ en acto respecto del acto primero y segundo. Pero si está del modo $1 .^{\circ}$ y $2 .^{\circ}$, no conoce, ergo (Ibid., p. 70 ). Si está del modo $3 .^{\circ}$, es asimismo imposible que conozca —entre los múltiples argumentos que ofrece Dietrich - porque no cabe ejercicio del acto segundo sin estar ejerciéndose el acto primero (pp. 71-85).

Por lo demás, el intelecto posible no puede ver a Dios por esencia, porque - como se ha indicado- conoce por especies. Añádase que, si esta facultad es por naturaleza pura potencia que nada conoce, no puede conocer a Dios 'por naturaleza'. Si a esto se objeta que por naturaleza el intelecto posible es un 'ente en acto', y que solo es en potencia respecto de las especies, se responde que - aparte de que tal afirmación es contraria a lo que sostienen los filósofos-, si el intelecto posible fuese un 'ente en acto por naturaleza', sería siempre cognoscitivo en acto (por su propia esencia), asunto que no acaece, pues nativamente es tabula rasa. Téngase en cuenta también que, de ser así, se movería a sí mismo y no requería ser activado, lo cual es obviamente falso.

En suma, el intelecto posible es pura posibilidad de conocer o pura 'potencia pasiva' $y$, por tanto, no puede ver a Dios 'por naturaleza'. Afirmar lo contrario es afirmar que una pura potencia es un puro acto, 'quod est absurdum'. Por último, si el intelecto posible está según el modo $4 .^{\circ}$, a saber, en acto respecto del acto primero y segundo, Teodorico afirma que 'nec hoc possibile est', porque no puede estarlo sin especie, y ya se ha indicado que la visión beatífica debe ser directa, no con mediación de especie alguna (Ibid., p. 85). 
c) Digresión metafísica. Seguidamente Teodorico aborda un largo rodeo que no es de teoría del conocimiento, sino metafísico, con el propósito de fundamentar lo que después va a exponer sobre los intelectos agente y posible. Se trata de la división de los entes. Los divide - como otros pensadores- en reales y de razón. Primero expone los reales, y después los lógicos o conceptuales. Respecto de los primeros enseña - la doctrina es peculiar suya- que son de tres tipos: los que son esencias en cuanto esencia; los que son sustancias en cuanto sustancia; y los que son accidentes. Los primeros, o no tienen principio, como la esencia de la primera causa, o lo tienen, como las criaturas que son inteligencias separadas, intelectos en acto por esencia. Los segundos tienen composición de materia y forma en la naturaleza (Ibid., pp. 88-89). Describe los terceros, los accidentes, de modo usual. Luego trata de la operación propia de estos entes, indicando que la operación de cada uno de dichos tipos es diferente de las demás, pues unos entes obran 'esentialiter', es decir, por su esencia; otros, 'substantialiter' o por su sustancia, y otros 'accidentaliter' o por disposiciones o formas accidentales ${ }^{18}$ (p. 90).

En el contexto de la explicación de los primeros tipos de entes, las esencias, y de sus operaciones propias, defiende su conocida tesis de que la 'essentia' equivale al 'esse' parecer en el que - pese a su importancia y oposición a la correcta tesis tomista- no nos detendremos ${ }^{20}$. Las acciones de las esencias - sigue - quedan en ellas; las de las sustancias presuponen un sujeto sobre el que recaen; las de los accidentes, a distinción de las anteriores, son extrínsecas (Ibid., pp. 92-93). El primer tipo de operaciones compete solo a los principios del todo separados; las segundas, a los cuerpos celestes e, instrumentalmente, a los del mundo; el tercero, son del mundo y se dividen en dos géneros: los de forma o virtuales (calor, frío, etc.) y los objetos de los sentidos (ejemplos: calor y frío en acto) (pp. 94). A su vez, el acto y la potencia se pueden decir de estos tres tipos de entes, pero - obviamente- de distinto modo.

18 Sobre las sustancias y los accidentes, ver: DIETRICH DE FREIBERG, Oeuvres choisies, l, Substances, quidités et accidents, Paris, Vrin, 2008.

19 "Essentia enim seu esse est prima et simplicisima et formalissima omnium intentionum in entibus" (Magistri, 2009, p. 91).

20 Si Teodorico hubiese admitido la distinción real tomista, la hubiese aplicado a la teoria del conocimiento $y$, consecuentemente, hubiese puesto el intelecto posible a nivel de esencia humana mientras que el agente a nivel de acto de ser, este autor hubiese superado el tomismo en su misma línea antropológica. Pero como no aceptó la distinción real, lo supera solo en teoría del conocimiento. 
Por lo que respecta a los entes de razón (los llama 'conceptionales') (Mojsisch, 2008), sostiene que estos son proporcionados a los reales, pues todo lo real puede ser conocido gracias al intelecto agente y al posible. A semejanza, pues, de los entes reales, distingue cuatro entes de razón: a) los que son algo 'essentialiter' o por esencia en cuanto esencia, que son conocidos por el intelecto agente; b) los que son conocidos por el intelecto posible; c) los conocidos por la cogitativa (o razón particular); d) los conocidos por los sentidos externos más por el sensorio común y la imaginación. Teodorico también distingue entre los entes de razón ('conceptionales') y los que conocen (ejemplos: el intelecto agente, el posible, etc.). Los primeros se llaman propiamente 'conceptionales', mientras que los segundos se llaman así solo relativamente. Estos últimos se dividen también en cuatro tipos, según sus operaciones propias: sentidos, cogitativa, intelecto posible y agente (Ibid., pp. 96-100).

Sentado lo que precede - la digresión metafísica-, el Maestro de Vriberg concluye que es imposible ver a Dios a través de especies. Por tanto, la visión beatífica no se puede alcanzar por el intelecto posible, porque ver a Dios "es incomparable e infinitamente más íntimo que todo principio de intelección consistente en especie creada" (Ibid., p. 101). Si a esto se objeta — por la misma razón- que ningún intelecto creado que opere por su esencia puede alcanzar tal visión, ya que la esencia divina es más infinita e íntima que todo cognoscente creado, que es finito, se responden dos cosas: a) conocer por esencia es íntimo, mientras que las especies son extrínsecas; b) tal intelecto creado conoce a Dios de modo finito, pero lo conoce por esencia, pues - como se ha dicho- la operación por la que conoce a Dios es su misma esencia, operación que procede de él y a él tiende ${ }^{21}$. En cambio, el intelecto posible no puede ver a Dios, por su esencia, porque su operación y las especies no equivalen a su esencia, y todo agente cuya operación es distinta de su esencia opera sobre algo que es 'extra se'. Por tanto, por sí solo no se vuelve a sí (pp. 103-104) y, en consecuencia, no puede conocer a Dios, ya que es lo más íntimo de toda naturaleza (pp. 103-104). Si a esto se objeta que el intelecto agente ('seu abditum mentis') es forma de nosotros y, por eso, no puede volverse a Dios que es más íntimo, se responde que el intelecto

21 "Talis intellectus, qui est intellectus in actu per suam essentiam, non prius habet essentiam seu esse suum absolute et postea seu natura posterius sua intellectione tendit in Deum sua conversione in ipsum, sed idem est respectus et habitudo et eadem intellectualis operatio, qua convertitur sua intellectione in Deum, eadem, inquam, cum ea, qua ab ipso eodem suo principio emanat per suam essentiam. Sua enim emanatione, qua intellectualiter emanat ab eo, est conversus in ipsum" (Magistri, 2009, p. 102). "Immo est omnino idem sua emanatio et in ipsum tentio, et omnino idem est sibi principium suae emanationis et terminus seu obiectum suae operationis et sub eadem ratione" (Magistri, 2009, p. 103). 
agente, en acto por su esencia, no es forma de otra cosa, sino que tiene la operación en su esencia y en esa intimidad conoce a Dios (p. 104).

Obviamente lo que precede choca con las tradicionales vías racionales, metafísicas, de acceso a Dios (ejemplo: las cinco tomistas), pero no es opuesto a la 'via interior' agustiniana. También se puede advertir lo siguiente: las pruebas racionales que demuestran la existencia de Dios son segundas, adquiridas, respecto de la natural y apertura primera de la persona humana a Dios. De otro modo: si somos capaces de activar o abrir esos en una tabula rasa nativa es porque el acto previo a esa facultad (el intelecto agente) que posibilita tal activación y apertura ya está abierto naturalmente a Dios.

\section{IV. a Parte: el modo de la visión beatifica}

En esta parte Dietrich expone dos asuntos; a) cómo es la visión beatífica; b) dónde radica el error de las opiniones equivocadas.

a) La visión beatífica es una unión inmediata, y debe realizarse por lo superior en nosotros. Tal unión se realiza por el intelecto agente, porque es lo superior en nosotros, es lo más semejante a Dios, y su operación intelectual es su esencia, lo más íntimo por parte del cognoscente, aunque lo conocido sea más íntimo y perfecto ${ }^{22}$. Por lo demás, es claro que esa nobleza e intimidad en el conocer no puede predicarse del intelecto posible.

b) Por lo que respecta a las diversas posiciones de los filósofos, Teodorico primero las expone y en segundo lugar las corrige. Indica que para Averroes la operación del intelecto agente sobre nosotros es distinta de su esencia, y se requiere que en la visión beatífica se una a nosotros como forma; añade además que el agente y lo entendido mueven al intelecto posible. Por otra parte, Alfarabí, Alejandro y asimismo el Comentador identifican lo conocido ('intellecta seu intelligibiles species') y el intelecto posible hecho en acto, y consideran que el intelecto agente se une al posible como forma. Para Teodorico, conocer cualquier cosa no es conocerla por la esencia divina, ni tampoco conocer dicha esencia. El error de tales opiniones radica en no

22 'Tum quia gradu naturae supremum nostri est, tum quia maxime Deo simile et ea similitudine, quae est imago Dei... tum etiam quia eius intellectualis operatio est essentia eius et secundum hoc quidquid est et operatur, totum est et operatur per suam essentiam" (Magistri, 2009, p. 105). 
distinguir entre principio activo de lo entendido y forma, pues el intelecto agente es principio activo, pero no forma como 'causa' (Magistri, 2009, p. 110).

Teodorico aduce otra prueba para afirmar que la bienaventuranza está ligada al intelecto agente. La demostración toma como base a la Sagrada Escritura, pues allí se lee que veremos a Dios por su esencia. Pero si esto no lo logra el intelecto posible, solo lo puede alcanzar el agente (Ibid., p. 111). Por lo demás, en esta vida la primera causa (Dios) mueve al intelecto agente, que "conoce a la primera causa, y fluye de ella en el ser” (p. 112). Por otra parte, admite - como Tomás de Aquino-que los dos intelectos - agente y posible-concurren para conocer ${ }^{23}$, que el conocer ordinario se ejerce abstrayendo de los fantasmas por el agente y comunicando las especies al posible, pero que hay otro modo de conocer que es el ser iluminado por conocimientos superiores al humano, también por especies, como por ejemplo la profecía. Con todo, estos conoceres son propios del intelecto posible, no del agente, que conoce sin especies (p. 118). En suma:

Por el intelecto agente entendemos con esa intelección por medio de la cual él mismo entiende, que es por su esencia, por la que siempre está referido a Dios, y en esto se perfecciona aquella vida bienaventurada, que se nos ha prometido por las Escrituras (Magistri, 2009, p. 119).

Con todo, en esta vida no conocemos a Dios directamente por el intelecto agente, sino formando especies por el posible (Ibid., p. 122).

Por último, el Maestro de Vriberg sale al paso de una objeción: ¿cómo es posible que el intelecto agente conozca siempre y no siempre seamos conscientes de ello, si, además, Aristóteles dice de los hábitos más altos que no conviene que los tengamos y que nos sean ocultos? Responde Teodorico que aunque la rudeza de algunos lleve a ignorar la constante operación del intelecto agente, sin embargo, los peritos no dudan al respecto, ya que toda operación intelectual del posible fluye de la intelección del agente, "pues sin esta interior, esencial y profunda intelección suya es imposible que él hiciese inteligibles en nosotros todas las cosas según el intelecto posible” (Ibid., p. 122). Tras el estudio de la historia de la filosofía referida a este tema se ha de corroborar

23 "Necessarium est... uterque istorum intellectuum tendat sua operatione in idem obiectum. Alias enim isti duo intellectus sic essent ab invicem disparati et seiunctae suae operations, quod ad invicen non haberent eam comparationem" (Magistri, 2009, p. 115). 
que el número de los 'peritos' es insignificante comparado con el de los 'rudos'. Por lo demás, el Teutónico advierte que el que tengamos hábitos y seamos conscientes de ellos, Aristóteles lo refiere, efectivamente, a los 'hábitos', no a lo intelectual del 'intelecto agente' que no es hábito, sino 'luz de su inteligencia, que es su esencia': "el intelecto agente es cierta realidad de la naturaleza en su sustancia y es substancialmente subsistente en su naturaleza" (p. 123). Lo que precede indica que los hábitos forman parte - como su palabra indica- del 'tener' y que lo que el hombre posee no le está oculto; en cambio, el intelecto agente no es del ámbito del tener, sino del ser o-como diría Teodorico- de la 'sustancia' o radical del hombre, asunto que es más difícil de conocer porque nuestro ser no cae bajo nuestro dominio.

\section{El intelecto agente en el Tractatus de intellectu et intelligibili}

Recuérdese que el título De intellectu et intellecto era una parte del De anima de Alejandro de Afrodisia; que el De intellectu era también un fragmento del De anima de Filipón; que ese fue también el título de una obra de Al-Kindi; que una obra de Al-Farabí se titula De intellectu et intelligibili. Que, en tiempos cercanos a Teodorico, Joannes Blondus publicó un De intellectu et intellecto. Es posible que el Maestro de Freiber conociese esos escritos. Con todo, aunque no hubiese tenido acceso a esos trabjos, de seguro sí conoció el De intellectu et intelligibili de Alberto Magno, al que se puede tomar como un precedente de esta obra. Este tratado de Teodorico está dividido en tres partes: en la primera se habla del intelecto en general; la segunda está dedicada al intelecto agente, y la tercera, al posible. En la I. ${ }^{\mathrm{a}}$ y III. ${ }^{\mathrm{a}}$ partes hay abundantes alusiones al intelecto agente, pero es en la II. ${ }^{a}$ donde encontramos multitud de capítulos que indagan sobre nuestro objeto. Vamos a exponer sucintamente las tesis centrales de estas partes.

\section{I. ${ }^{\text {P Parte: }}$ del intelecto en general}

La Prima Pars del Tractatus comienza indicando que cada cosa es por su propia operación (tema ya estudiado en el De visione beatífica), a lo que seguidamente añade que hay una doble operación tanto en lo corporal como en lo intelectual: una activa y otra pasiva. La pasiva intelectual se atribuye al intelecto posible, aunque en sentido propio 'operatio pasiva non convenit intellectibus', lo cual es correcto. En efecto, este es un buen comienzo, porque todo conocer es siempre activo. En esta Parte no se centra el 
estudio en el intelecto agente y, por tanto, abreviamos en extremo su exposición. Un poco más adelante, en De duplici genere intellectuum, distingue el intelecto posible del agente, y dice de este que actúa según su ser, y que "a semejanza de las sustancias separadas no está de ninguna manera en potencia pasiva según el modo de aquellas sustancias y es sustancia... cualquier cosa que hay en él es su sustancia” (Magistri, 2009, p. 140). El intelecto posible, en cambio, es potencia pasiva. Más abajo alude a la necesidad de que en el intelecto exista una virtud activa que active algo fuera de sí (p. 143).

\section{II. ${ }^{a}$ Parte: del intelecto agente}

Comienza enseñando que lo propio del intelecto es la semejanza con todas las cosas, y enseguida alude al pasaje aristotélico De Anima, 1. III, cap. 5, en el que se distinguen el intelecto agente y el posible: "uno y otro de estos intelectos son por esencia semejantes a todos los entes, aunque uno según el acto, a saber, el agente, y el otro según la potencia antes de entender, a saber, el intelecto posible" (Magistri, 2009, p. 146). Al final de este epígrafe añade sobre el intelecto posible que "él mismo es todo ente según participación, ya que la participación desciende a él mismo cuando se hace en acto por el intelecto agente, que es principio causal del acto de entender del posible" (p. 147).

El epígrafe n. 2 de esta parte titulado Quod intellectus agens est principium causale substantiae animae sicut cor in animali, enseña que el intelecto agente es un 'principio humano intrínseco'.

El agente es por sí principio y forma inteligible en el intelecto posible, porque la forma inteligible es toda la esencia del intelecto posible (...). El mismo intelecto posible, según que está en potencia no es sino pura posibilidad sin ninguna naturaleza positiva (...) esta forma inteligible es cierto accidente o cierta disposición accidental. Pero el intelecto agente actúa en ella por su esencia por el hecho de que no hay otro principio activo en sí sino su esencia (Magistri, 2009, p. 147).

Afirma también que el intelecto agente es, por naturaleza, previo y simultáneo a la esencia del alma; previo, porque la activa con dicha disposición accidental, y 
simultáneo a la sustancia del alma antes de que obre en ella. "Esa simultaneidad no es otra cosa sino la coexistencia con las cosas por esencia” (Ibid., p. 148).

Pero el intelecto agente no es ni la esencia ni lo mismo por esencia con esas cosas como aquellas que son una por esencia - las compuestas de materia y forma-, pues no obraría en ellas alguna disposición accidental como la forma no obra en el propio sujeto. Por tanto, es necesario que sea simultáneo con ellas de modo que una de ellas sea causa de otra por esencia. $Y$ así se refiere el intelecto agente respecto de la sustancia o esencia del alma (Magistri, 2009, p. 148).

El Maestro de Vriberg advierte que, según San Agustín, en el alma se encuentra cierta intimidad ('intraneitatem') de su sustancia que no se une al cuerpo, en la cual se ejercen operaciones que no son corporales, sino espirituales ${ }^{24}$. Se afirma que "el intelecto agente es principio causal de la sustancia racional" (Ibid., p. 150), es decir, principio vital intrínseco al alma racional que la anima. $\mathrm{Y}$ "esta interioridad no es sino la identidad substancial" (p. 151), o sea, su principio de individuación; principio de la vida intelectual que es la esencia del alma ${ }^{25}$. El intelecto agente es 'causa' del alma, lo cual indica que es distinto y superior a ella. Si este pensador hubiese retomado la distinción real tomista entre acto de ser y esencia hubiese podido afirmar una gran verdad: que el intelecto agente equivale al 'actus essendi', mientras que el alma (que mira a animar lo inferior a ella) conforma la 'essentia hominis'. Que sea 'causa del alma' se puede entender en el sentido de que la esencia nace del acto de ser. Es 'causa' del alma, pero, obviamente, no es causa 'material', ni tampoco 'formal' (que no está separada de la materia); no es asimismo causa 'final' (porque esta no obra para constituir la realidad en su ser). Es, pues, causa 'eficiente', como el corazón respecto de las demás partes del cuerpo (Ibid., pp. 152-154). Hasta aquí la exposición del autor. Ahora bien, aunque Dietrich emplee el modelo de la tetracausalidad, hay que decir que dicho paradigma, tomado de la realidad física, solo se debe emplear analógicamente al explicar lo espiritual, pues en sentido preciso el intelecto agente no es causa ninguna. También lo compara a la forma natural, pero dice diferir de ella porque tal intelecto es intelecto en acto por esencia, asunto que no se puede predicar

24 "Sic ergo quantum ad sententiam Augustini in anima quaedam intraneitas secundum aliquem modum qualitativum substantialem, secundum quem non est unita corpori, et propter hoc exercet quasdam operations vitales non comunicatas corpori tamquam subiecto talium passionum" (Magistri, 2009, p. 150).

25 "Intellectus agens est idem cum essentia animae" (Magistri, 2009, p. 150). 
de la forma. En resumen, para el Maestro Teutónico "el intelecto agente es principio causal intrínseco del alma, no solo en cuanto a sus operaciones intelectuales, sino también en cuanto a la esencia del alma” (Ibid., p. 155).

Por otra parte, "el intelecto agente es singular en los singulares y uno de cada uno, y se multiplica y numera según los hombres singulares" (Ibid., p. 155) ${ }^{26} \mathrm{y}$, precisamente por eso, es el principio propio que mueve a cada hombre. Según Teodorico, en las sustancias separadas el 'género' se toma del 'esse', que es lo más simple; la 'especie' se toma de la 'vida'; y el 'individuo' del 'intelecto agente’ (pp. 157-158)27, “y así el intelecto agente tiene según su sustancia razón de individuo en el género de los seres intelectuales" (p. 158). En suma, el intelecto agente incoa el principio de individuación del alma, estando en esta de modo dispositivo, y en el todo (con el cuerpo) de modo completivo (p. 159). En cuanto a la comparación de los diversos intelectos agentes entre sí, el Maestro de Vriberg opina que "nada obliga a decir que todos los intelectos agentes sean iguales entre sí en cuanto a la perfección y nobleza de naturaleza” (p. 161). Ante esta afirmación cabe decir, sencillamente y una vez más, esto: ¡Genial!

En efecto, aunque en nuestra altura histórica no sea 'políticamente correcto' afirmar lo que sigue, es claro que si no hay dos personas humanas iguales, y dado que la distinción en lo real es siempre jerárquica (pues la igualdad es exclusivamente mental), no cabe más remedio que, si el intelecto agente es principio de individuación de los seres personales, en cada uno de ellos debe ser necesariamente distinto según jerarquía, o sea, 'ut unus sit necesario nobilior et perfectior alio' (Ibid., p. 161). Sin embargo, si bien eso es así 'nativamente', es claro que cualquier intelecto agente puede ser elevado por Dios, claro está, si tal intelecto agente acepta dicha elevación.

De manera que cualquier intelecto agente puede ser más que nativamente es. En cuanto a la cuestión de quién conoce la superioridad o inferioridad de los intelectos agentes, la respuesta se deduce de lo precedente, pues si estos fluyen de Dios y a él se refieren, solo él lo sabe, asunto que, por lo demás, es fácilmente comprensible, pues solo Dios conoce la intimidad humana de cada quién. En estos pasajes también se nota cuán

26 Más abajo insite que "intellectum agentem esse singulum singulorum hominum et numerari secundum numerationem eorum et esse vere individuum" (Magistri, 2009, p. 159).

27 Más abajo añade: "ex intellectu agente et substantia animae aggregatur unus ens, quod est unum per essentiam" (Magistri, 2009, p. 158). 
lejos está Teodorico de la usual y rebajada manera de entender el intelecto agente humano por la mayor parte de los comentadores, que lo reducen al papel abstractivo ${ }^{28}$.

El individuo supone un añadido a la esencia, considerada como especie, pues no es toda la esencia. De este estilo es el intelecto agente. Teodorico se pregunta también acerca de la cuestión de la eternidad del mundo, otra aparente digresión metafísica en cuya resolución reconducirá el agua a su molino noético. Para unos esta hipótesis no tiene lugar, porque para ello habría que admitir un número infinito de hombres, de intelectos agentes, lo cual es imposible. Pero para este eminente maestro, aunque fuese posible que Dios produjera el mundo ab aeterno, de ahí no se seguiría que los intelectos agentes fuesen infinitos (Ibid., p. 168).

En definitiva:

El intelecto agente es principio causal intrínseco en el alma y está en el alma como el corazón en el animal. Como es cierto individuo y singular en los singulares, se multiplica según la multiplicación de ellos, de los que es principio (Magistri, 2009, p. 169).

Por lo demás, pueden multiplicarse 'in infinitum'. En cuanto a su esencia, es sustancia en acto; de ninguna manera es potencia esencial o accidental; es deiforme, pues en el intelecto agente está la imagen divina, porque en el ser procede de Dios, y es propio de él alcanzar la visión beatífica (Ibid., pp. 170-171). ¿Cómo procede de Dios? "Proceder como imagen es proceder conociendo a aquél de quien procede, ya que tal conocimiento es la misma procesión y aceptación de su esencia” (p. 172). Las cosas que no son intelectuales proceden de Dios según la razón divina; pero el intelecto agente procede de la razón divina, que es proceder intelectualmente, es decir, en conformidad de imagen con el intelecto divino; imagen, que por proceder de ese modo, es perfecta (pp. 173-175).

En cuanto al objeto del intelecto agente, Teodorico deduce de lo que precede tres cosas: a) es su principio del cual procede entendiendo, y en ese entender consiste su

28 Por lo demás, el intelecto agente de los ángeles es superior al de los hombres, porque esa superioridad se manifiesta por sus efectos, pues ejercen superiores operaciones que los hombres (Magistri, 2009, p. 163). En cuanto a la célebre cuestión de si los ángeles (como los hombres) pertenecen a una misma especie, este pensador sajón afirma que "no hay inconveniente en decir que todos los órdenes de espiritus convienen en la especie y se distinguen individualmente entre si" (Magistri, 2009, p. 164). 
esencia y aceptación; b) es su propia esencia, a la que entiende; c) es la universalidad de los entes, porque su cognición los comprende todos (Ibid., p. 175). Con todo, "aunque atienda a tres cosas en su intelección, sin embargo, uno es el entender" ( $\mathrm{p}$. 175), como el intelecto divino, del que procede, que con un solo acto se entiende a sí y a las demás cosas. Sin embargo, de esos tres temas, el principal objeto del intelecto agente es conocer 'su principio por esencia', a saber, el ser divino. Si a esto se objeta que, dado que su principio dista mucho de su propia esencia, no puede conocer ambos, se responde que el intelecto agente no conoce nada fuera de sí, puesto que no conoce sino su esencia y en ella su principio, puesto que le es íntimo ('magis intimum quam ipse sibi'), y lo demás lo conoce por su esencia y en su principio.

El intelecto agente es, pues, una naturaleza determinada, distinta de las demás, que conoce su esencia directamente, por sí, inmediata y formalmente, y subordina su esencia a su principio (Ibid., p. 177). Es distinto de su principio, Dios, pero no es extrínseco a él; por eso no lo conoce 'extra se'. Además, como los bienaventurados, conoce las demás cosas viéndolas en Dios. Esto no quiere decir que todo lo que conocemos lo conozcamos en Dios (tesis propiamente ontologista), puesto que Dietrich ha afirmado que no es el mismo el conocer del agente que el del posible. Este no conoce en Dios. En cambio, en el agente tiene dos modos de conocer su esencia: una directa, por sí e inmediata; otra, indirecta, conociendo su principio, en el que se conoce a sí y a las demás cosas en él, según el modo propio del principio. En estos pasajes se nota en Teodorico la influencia de Eckhart. Conviene precisar, no obstante, que para ambos pensadores el hombre no se diluye o identifica con Dios.

\section{III. ${ }^{\text {a Parte: }}$ del intelecto posible}

En esta parte lo primero que demuestra Teodorico es que el intelecto posible no es un ente en acto. Tampoco es un ente positivo que esté en potencia respecto de la forma sustancial, porque algo positivo en la naturaleza se funda en algún acto y es sustentado por él, pero este intelecto carece de ello. No es tampoco un ente positivo que existe en potencia respecto de una forma accidental, porque tal forma supone un acto sustancial, pero este intelecto no lo supone. Asimismo no es sustancia, sino un accidente. Desde luego es separado del órgano corpóreo, pero no una 'sustancia separada'. Es pura potencia pasiva que recibe las especies abstraídas por el intelecto agente (Magistri, 2009, pp. 179-182). 
Si bien en la realidad ('in esse naturae') es un accidente, en cuanto potencia cognoscitiva tiene el modo de una sustancia. Una sustancia es un ente 'per se'; un accidente es un ente 'in alio'. Se parece a la sustancia por dos motivos: porque es separado, y por su operación, ya que así como la sustancia constituye la cosa real por sus principios, así el intelecto posible entiende la cosa en sus principios. Puede conocer todas las cosas y cuando las conoce, las conoce de modo universal, pero él es particular, y según esto se numera en los diversos cognoscentes (Ibid., pp. 183-184). Frente a Averroes, Teodorico niega que sea la misma sustancia que el intelecto agente y que sea 'sustancia separada', pues es una potencia humana ${ }^{29}$. El objeto del intelecto posible es triple: en primer lugar, la quididad, que en las sustancias es la forma, y en los accidentes es la sustancia en la que estos inhieren; en segundo lugar, el mismo quid, o sea, la sustancia compuesta de materia y forma; en tercer lugar, los objetos mentales. En lenguaje tomista se podría decir que el primer objeto es el 'abstracto'; el segundo, el 'concepto' (es incorrecto confundir el abstracto con el concepto); el tercero, los entes de razón.

Teodorico afirma que el acto del intelecto posible procede del acto del intelecto agente (Ibid., p. 199). Admite también que todas las cosas que conocemos intelectualmente, las conocemos en la luz de la primera verdad, que es $\operatorname{Dios}^{30}$, en lo que dice seguir la sentencia de San Agustín ${ }^{31}$. Por último, añade que el intelecto posible se refiere al agente como a su principio activo, ya que este hace al posible cognoscitivo en acto. El posible "procede del agente entendiendo, y procediendo entiende y a él se convierte. Y

29 "Cum suma vita hominis sit ut vivat intellectualiter, non est verosimile, ut praecipuum huius vitae principium, quod est intellectus agens, non approprietur uniquique homini et non sit intrinsecum sibi. Alioquim non plus diceretur homo vivere per operationem intellectus agentis in ipso quam paries, quando coloratur ab extrinseco agente" (Magistri, 2009, pp. 185-186).

30 Más adelante añade: "omne quod intelligitur non intelligitur nisi in sua ratione, quia hoc est intelligere, id est intus legere, quod proprium est intellectus, sicut et nomen ipsum praetendit. Talis autem rei ratio splendet in intellectum possibilem ex suo principio intellectualli, quod est intellectus agens inmediatum. Et quia causa primaria plus influit quam causa secundaria, ideo huiusmodi ratio rei plus splendet a primo principio intellectuali, quod Deus est, in intellectum quam ab immediato principio, quod est intellectus agens. Et non ponit in numerum, secundum quod invenitur in Deo et secundum quod invenitur in intellectu agente. Quamvis enim, inquantum est res quaedam, sit abstractius et separatius et per consequens minus determinate in Deo et in intellectu magis determinate, sicut se habet in omnibus causis essentialibus, tamen non inquantum ratio, quae est unius modi et unius intentionis in Deo et in intellectu agente. Et secundum hoc videndo rem aliquam in sua ratione est videre eam in lumine primae veritatis, quae Deus est secundum Augustinum (...) et non solum hoc, verum etiam videtur in lumine intellectus agentis tamquam in immediato principio" (Magistri, 2009, p. 207).

31 Ver: De vera religione, XXXI, 57, (PL 34, 147-148). 
así la misma procesión es intelección y a la inversa, ya que son una cosa en la realidad con distinción de razón" (p. 208). El posible conoce al agente porque de él procede:

Como quiera que el intelecto (posible) procede en el ser del intelecto (agente), lo primero que conoce es su principio, por el que procede conociendo, por el que conoce su esencia (...). Lo segundo que conoce es su propia esencia por la que se conoce a sí mismo y a su principio (...). En tercer lugar, entendiendo su esencia entiende la realidad externa, de la que es ejemplar (Magistri, 2009, p. 209).

Sin embargo, hay que afirmar que el intelecto posible no conoce ni lo superior a él (el intelecto agente) ni a sí mismo sino solo en parte, a saber: los objetos pensados que forma, los cuales son conocidos por sus actos; y sus actos, los cuales son conocidos por sus hábitos cognoscitivos adquiridos. Pero él mismo no se conoce como potencia. Para eso se requiere de un instrumento nativo al intelecto agente que la tradición medieval denomina sindéresis.

\section{El intelecto agente en la quaestio utrum in deo sit aliqua vis cognitiva inferior intellectu}

La Tabula de esta Quaestio ${ }^{32}$ está dividida en dos partes: en la primera se responde a la cuestión planteada; en la segunda contradice la sentencia que algunos sostenían sobre el intelecto posible. Cada una de las partes consta de varios epígrafes. Para responder negativamente a la cuestión, primero el Teutónico se ve urgido a que exponer cuáles son las distintas 'virtudes' cognoscitivas.

\section{La exposición de la Quaestio}

En la I. ${ }^{\text {a }}$ parte Teodorico escribe que son tres los géneros de conocimiento: el sensible (sentidos externos e internos), el racional (intelecto posible), y el intelectivo ('qui est intellectus semper in actu', intelecto agente). Los tres difieren entre sí por el objeto, pues el primero conoce lo singular; el segundo, lo universal; el tercero, la esencia simple. También difieren en cuanto a su eficacia noética, pues el primero abstrae de

32 Quaestio utrum in Deo sit aliqua vis cognoscitiva inferior intellectu (Magistri, 2009, p. 293). 
la materia; el segundo de lo sensible; el tercero, de ambos, y por eso conoce a Dios. Dicho esto, añade que "en Dios no existe ningún conocer inferior al intelectivo" (Magistri, 2009, p. 296). En cambio, en las 'sustancias espirituales' hay que poner algún conocer inferior al intelectivo, porque conocen lo singular. Tal potencia es la cogitativa ('phantastica cogitativa') (Ibid., p. 299): "por tanto, en cualquier sustancia que tiene intelecto, que sale de la potencia al acto, es necesario que exista una virtud cognitiva inferior al intelecto" (p. 302).

En atención a lo que precede, Teodorico dedica la II. ${ }^{a}$ parte de este trabajo a rectificar la opinión de los que sostienen que el intelecto agente y el posible son dos potencias que nacen de la esencia del alma (es decir, la posición tomista). No trata en directo del agente por centrarse en el posible. De este dicen que es un 'accidente separado', lo cual -para el Maestro de Vriberg-, es contradictorio, por muchos motivos: porque el accidente dice relación a la sustancia (Ibid., p. 303). Además, si es potencia, requiere de un acto que la actualice. Si a eso se objeta que por su esencia el intelecto posible no es potencia, sino algo en acto a lo que compete el ser en potencia respecto de la forma, se responde que eso es absurdo, porque un intelecto por esencia (como los ángeles) es cognoscente, no una tabula rasa. Asimismo tendría una naturaleza determinada $y$, por tanto, no pasaría de la potencia al acto. Añádase que si es una 'forma simple' (sin composición) - como opinan- es imposible que pase de la potencia al acto. $\mathrm{Si}$, además, es determinable, es porque no es simple; etc. (pp. 305-307). En suma, un ente en potencia se determina a un acto intrínseco perfectivo, y para determinarse a este, requiere de un ente en acto superior extrínseco, a saber, del intelecto agente (pp. 308-314). Hasta aquí - en síntesis- las claves del Maestro Teodorico sobre el intelecto agente; tesis que no fueron ni muy conocidas, ni - en el caso de serlomuy aceptadas. Pasemos ahora a exponer, en el próximo epígrafe, dos testimonios de primera época, una del rechazo de las mismas; otra, de su aceptación.

\section{Conclusiones}

Tras la lectura de estos trabajos de Teodorico se puede sostener que estamos (de entre conocidos) ante los escritos en que más abundantemente se ha investigado el tema del intelecto agente y, seguramente también, los que con más profundidad lo han llevado a cabo. Pero si lo que se acaba de indicar es verdad, ¿por qué de este autor apenas se hacen eco los libros de historia de la filosofía? Seguramente por ningún 'por qué’ o razón, sino por falta de ella. Efectivamente, suele suceder que los excelentes 
pensadores pasan desapercibidos, pues la historia honra a los célebres, no necesariamente a los mejores. En correlación con esto los historiadores de la filosofía se fijan más en las cuestiones metafísicas que en las de teoría del conocimiento, máxime en el punto que nos ocupa; y es claro que Dietrich von Freiberg - a distinción de Tomás de Aquino- destaca más en las segundas que en las primeras.

En cualquier caso, de la lectura de sus tratados podemos entresacar las siguientes sintéticas conclusiones sobre el intelecto agente: 1) Es imagen de Dios. 2) Es sustancia. 3) Es singular en los singulares y uno en cada uno, y se multiplica y numera según los hombres singulares, (que no son infinitos en número), porque es principio de individuación. 4) Los intelectos agentes no son iguales entre sí en cuanto a la perfección y nobleza de naturaleza. 5) Siempre entiende en acto. 6) Se entiende a sí mismo, a las demás cosas y a Dios por su esencia (es 'capax Dei'). 7) Al conocer su esencia, necesariamente conoce su principio. 8) Al conocer su principio, no conoce fuera de sí, sino dentro de sí. 9) No difiere de su operación. 10) Conoce sin especies. 11) Es principio causal intrínseco del alma. 12) Es principio activo y perfectivo del intelecto posible (el intelecto posible procede en el ser del intelecto agente). 13) Media entre las demás realidades corpóreas y Dios. 14) Procede de Dios y a él vuelve como a su principio. 15) Procede de Dios conociéndole, ya que tal conocimiento es la misma procesión y aceptación de su esencia. 16) Alcanza la visión beatífica.

De estas tesis, la $1 .^{\mathrm{a}}, 3 .^{\mathrm{a}}, 4 .^{\mathrm{a}}, 5 .^{\mathrm{a}}, 7 .^{\mathrm{a}}, 8 .^{\mathrm{a}}, 9 .^{\mathrm{a}}, 10 .^{\mathrm{a}}, 11 .^{\mathrm{a}}, 12 .^{\mathrm{a}}, 14 .^{\mathrm{a}}, 15 .^{\mathrm{a}}$ y $16 .^{\mathrm{a}}$ son -a mi juicio-correctas. Las 2. $.^{\mathrm{a}}, 6 .^{\mathrm{a}}$ y $13 .^{\mathrm{a}}$, en cambio, —según mi parecer-son matizables: la $2 .^{a}$ es verdad si 'sustancia' se entiende como 'subsistencia'; la $5 .^{\text {a }}$ es corregible, porque el intelecto agente no se entiende a sí mismo y a las demás realidades 'directamente', sino mediante hábitos innatos; en cambio, su tema directo es el ser divino. La 13. a se puede rectificar por lo mismo, a saber, porque no media 'directamente' entre Dios y las demás realidades, sino que para ello se sirve de hábitos como de instrumentos.

Ninguna de las tesis siguen las líneas de interpretación anteriores y usuales del intelecto agente, a saber: a) 'sustancia separada' (comentadores griegos clásicos, árabes y judíos medievales, y averroísmo latino); b) 'potencia' y, por tanto, 'accidente' (Tomás de Aquino y seguidores); c) 'negación' (Durando), 'distinción meramente formal' (Escoto) o 'nominal' (Ockham) del posible; d) 'hábito' —adquirido (San Buenaventura), o innato (Alfonso de Toledo)—; e) 'acto de ser' (San Alberto Magno); f) 'alma de la humanidad (Filopón); g) la misma alma (Enrique de Gante). h) la 'memoria' (Godofredo de Fontibus). Por tanto, estamos ante un pensador original, 
aunque lo más relevante de él no es esto, sino el haber descubierto que el intelecto agente ocupa la cúspide del ser humano y haberlo puesto en correlación directa con el ser divino.

\section{Referencias}

De librea, A. (1984). La mystique renane. Paris: De seuil.

Flash, K. (2008). Dietrich von Freiberg und Siger von Brabant. Eine studie zur 'Schule' Albert des Grossen. En Per perscrutationem philosophicam, 127-141. Hamburg: Meiner.

Hipona, A. (s.f.). De vera religione. XXXI, 57, (PL 34, 147-148).

Imbach, R. (1979). Gravis iactura verae doctrinae. Prolegomena zu einer Interpretation der Scrift Der ente et essentia Dietrichs von Freiberg O.P. Freiburger Zeitscrift für Philosophie und Theologie, (26), 369-425.

Imbach, R. (1997). Lantithomisme de Thierry de Freiberg. Revue Thomiste, (97), 245-258.

Krebs, E. (1906). Die Schriften Meister Dietrich. En Beiträge zur Geschiche der Philosophie und Theologie des Mittelalters, 1-124.

Magistri, T. (2009). De visione beatifica. En Corpus Philosophorum Teutonicorum Medii Aevi, 1, 9-124. Hamburg: Felix Meiner Verlag.

Magistri, T. (2009). La Quaestio utrum in Deo sit aliqua vis cognoscitiva inferior intellectu. En Corpus Philosophorum Teutonicorum Medii Aevi, 3, 283-315. Hamburg: Felix Meiner Verlag.

Magistri, T. (2009). Tractatus de intellectu et intelligibili. En Corpus Philosophorum Teutonicorum Medii Aevi, 1, 131-210. Hamburg: Felix Meiner Verlag.

Maurer, A. (1956). The De Quiditatibus Entium of Dietrich of Freiberg an dits Criticism of Thomistic Metaphysics. Médieval Studies, (18), 173-203.

Mojsisch, B. (1997). The theory of intellectual construction in Theodoric of Freiberg. Bochumer philosophisches Jahrbuch für Antike und Mittelalter, 2, 69-79. 
Mojsisch, B. (2008). Die Theorie des bewusstseins (ens conceptionale) bei Dietrich von Freiberg. En H. von Beccarisi. Per perscrutationem philosophicam, 142-155. Hamburg: Meiner.

Winkler, N. (1999). Dietrich von Freiberg und Meister Eckhart in der Kontroverse mit Thomas. En B. Mojsisch (Ed.). Dietrich von Freiberg: Neue Perspektiven seiner Philosophie, Theologie und Naturwissenschaft. Amsterdam: J Benjam 